\title{
Isotope Effect on Eutectic and Hydrate Melting Temperatures in the Water-THF System
}

\author{
C. Y. Jones, ${ }^{1}$ J. S. Zhang, ${ }^{2}$ and J. W. Lee ${ }^{2}$ \\ ${ }^{1}$ Department of Chemistry, Hamilton College, Clinton, NY 13323, USA \\ ${ }^{2}$ Department of Chemical Engineering, The City College of the CUNY, NY 10031, USA \\ Correspondence should be addressed to C. Y. Jones, cyjones@hamilton.edu
}

Received 24 July 2009; Accepted 3 December 2009

Academic Editor: Angelo Lucia

Copyright $(2010$ C. Y. Jones et al. This is an open access article distributed under the Creative Commons Attribution License, which permits unrestricted use, distribution, and reproduction in any medium, provided the original work is properly cited.

\begin{abstract}
Differential scanning calorimetry was used to study the effect of isotopic substitution on the eutectic and melting temperatures in the water-tetrahydrofuran (THF) system with THF molar fractions near the stoichiometry of the hydrate phase. Deuteration of the host causes an opposite effect from that of the guest with respect to the hydrate liquidus curve and eutectic melting temperature. The eutectic temperature in $\mathrm{D}_{2} \mathrm{O}$-containing systems is approximately $3.7 \mathrm{~K}$ higher than that in $\mathrm{H}_{2} \mathrm{O}$-containing systems. The melting temperatures of THF and deuterated THF hydrates increase by roughly $3.5 \mathrm{~K}$ with heavy water. The inclusion of deuterated THF causes a depression of the hydrate liquidus temperatures and a small but measurable effect on the eutectic temperature.
\end{abstract}

\section{Introduction}

Tetrahydrofuran (THF, $\mathrm{C}_{4} \mathrm{H}_{8} \mathrm{O}$ ) hydrate plays a prominent role in the study of numerous hydrate properties, for example, their formation [1], structure [2], and dynamics [3]. The reasons for this prominent role are practical ones: THF is water-soluble, is readily available as both hydrogenated and fully deuterated compounds of high purity, and its aqueous solutions form hydrates under mild conditions at atmospheric pressure. Maximum melting points for THF hydrate have been reported in the range of (277.15278.15) K [4-8]. Because of the ease with which THF hydrate forms, and the fact that at room temperature water and THF are completely miscible, the rather complex phase behavior taking place in this system is not apparent. In fact, the tetrahydrofuran-water system displays complex liquidphase behavior, with regions of high-temperature and lowtemperature immiscibility; several features of the $P-T-x$ space of the THF-water system are shown in Figure 1. Matouš et al. [4] identified a broad, closed loop with lower and upper consolute temperatures of approximately $344 \mathrm{~K}(53.5 \mathrm{wt} \%)$ and $410 \mathrm{~K}$ (48 wt\%), respectively. Their study, and a more recent one by Balevicius et al. [5], were undertaken to characterize the critical behavior in the system and clarify and describe substantial isotope effects on liquid miscibility. Rosso and Carbonnel [6] and Carbonnel and Rosso [7] determined the phase diagram at low temperatures and found a miscibility gap with a critical temperature of approximately $286 \mathrm{~K}$ and a peritectic reaction at $278 \mathrm{~K}$ forming the structure II clathrate hydrate at a composition of $17: 1 \mathrm{H}_{2} \mathrm{O}$ : THF. This makes the structure II hydrate an incongruently melting phase. A transformation of the structure II hydrate to the structure I form has been observed at $255 \mathrm{~K}$ and $34 \mathrm{MPa}$ [8] and $77 \mathrm{~K}$ and $131 \mathrm{MPa}$ [9]. Manakov et al. [10] characterized the THFwater system at high pressure and found a high-temperature hydrate phase with room temperature stability in the range of 4.9-30 MPa.

Studies have been conducted on both the hydrogenated and deuterated forms of THF hydrate, depending on the nature of the property being investigated. However, the dramatic nature of the H/D isotope effect causes changes in both the physical and chemical properties of binary mixtures or water and water-miscible organic solvents. Oleinikova and Weingärtner [11] studied the effect of the H/D isotopic composition on the shape of the immiscibility loop in the THF-water binary system. In these studies, they observed a shrinking of the miscibility gap in the presence of THF- $d 8$ and a widening of the gap in the presence of $\mathrm{D}_{2} \mathrm{O}$. Isotope 


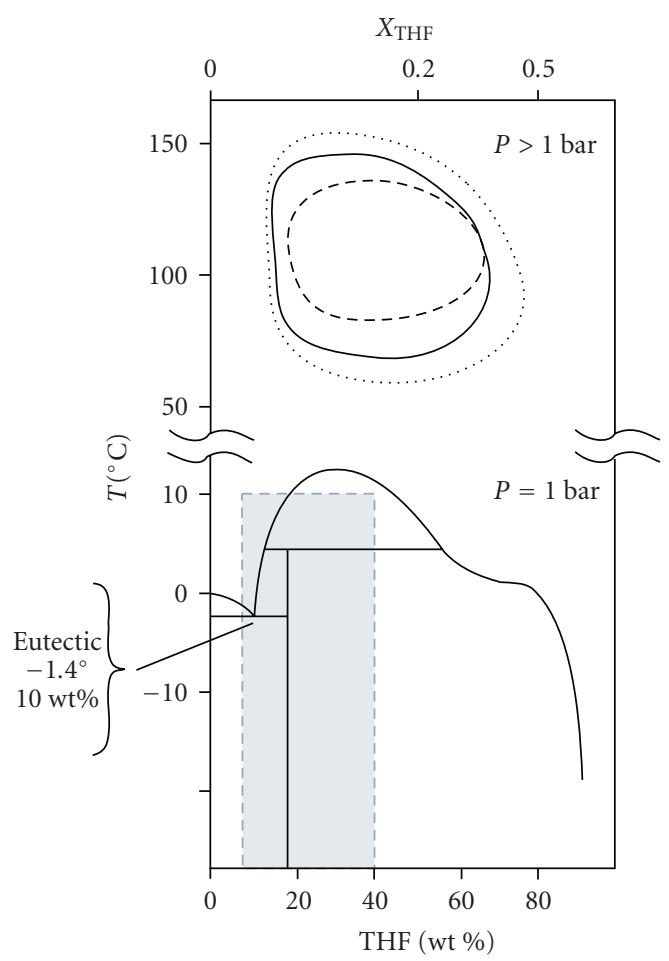

Figure 1: Schematic of the $T-x$ phase diagram of the water-THF system (solid lines), taken from the published phase diagrams of Rosso and Carbonnel $\left(T<50^{\circ} \mathrm{C}\right)$, Carbonnel and Rosso $\left(T<50^{\circ} \mathrm{C}\right)$ and Balevicius et al. $\left(T<50^{\circ} \mathrm{C}\right)$. The gray solvus curves represent the widening (dotted) and narrowing (dashed) of the miscibility gap with deuteration of water and THF, respectively.

effects are also evident in the crystal structure determinations of clathrate hydrates, due to the covalent distances being longer and the hydrogen bonds being stronger in $\mathrm{D}_{2} \mathrm{O}$ than those in $\mathrm{H}_{2} \mathrm{O}$.

Understanding how the behavior in the THF-water and other hydrate systems is affected by isotope substitution is critical to developing a complete understanding of their stability. Hanley et al. [12] previously measured the isotope effect on cooling curves in the THF-water system, where substitution with $\mathrm{D}_{2} \mathrm{O}$ shifts the curve to higher temperatures. Based on the results of Balevicius et al. [5] a guest isotope effect on the phase equilibria of the solid phases might be predicted as well. In this work, we use differential scanning calorimetry (DSC) to study the effect of isotopic substitution in both THF and water on the eutectic and hydrate melting temperatures in water-tetrahydrofuran systems. The quantum effects responsible for the H/D isotope effect on the tetrahedral, hydrogen-bonded structures formed by $\mathrm{H}_{2} \mathrm{O}$ and $\mathrm{D}_{2} \mathrm{O}$ are well known; however, the $\mathrm{H} / \mathrm{D}$ effects on hydrate crystal structure parameters and the effect of guest H/D substitution on hydrate properties have not been studied systematically, even though results from studies of both hydrogenated and deuterated hydrates are used routinely as models for natural hydrate systems.

\section{Experimental}

2.1. Materials. Tetrahydrofuran with a purity of $+99 \%$ was purchased from Sigma-Aldrich. Tetrahydrofuran- $d_{8}$ with 99.9 atom\% D and deuterium oxide with $99.5 \% \mathrm{D}$ were obtained from Sigma-Aldrich. All chemicals were used as received without further purification. Deionized water was produced in our lab with a resistivity of $18 \mathrm{M} \Omega \mathrm{cm}$.

2.2. Apparatus and Procedures. The eutectic and melting points were determined with a MicroDSC purchased from Setaram. A detailed description of the MicroDSC was given in a previous paper [13]. The solutions were prepared gravimetrically. The sample cells was charged with approximately $20 \mathrm{mg}$ of solution, and the reference cell was empty. The sample and reference cell were cooled down to a low temperature at a rate of $3 \mathrm{~K} \mathrm{~min}^{-1}$, which was usually below $248 \mathrm{~K}$, and then heated to a temperature below the eutectic point at a rate of $1.2 \mathrm{~K} \mathrm{~min}^{-1}$, followed by heating the cells at a rate of $0.1 \mathrm{~K} \mathrm{~min}^{-1}$ up to $280 \mathrm{~K}$ or $285 \mathrm{~K}$, to allow both the ice and hydrate phases to melt. The cycle of coolingheating was repeated at least three times for each sample, and the average values are reported in this work. The onset temperature of the eutectic melting peak is taken as the eutectic temperature, and the maximum temperature of hydrate melting peak is taken as the melting temperature.

\section{Results and Discussion}

3.1. Cooling Behavior. Figures 2-4 present typical cooling and heating thermograms for water-rich and THF-rich solutions. In the water-rich region, as shown in Figure 2, only a single exothermic peak is detected in the first cooling step, which is due to the freezing of hydrates and ice simultaneously. However, two exothermic peaks are observed in the subsequent cooling steps. The first and second peaks correspond to the freezing of hydrates and ice, respectively. The freezing temperature of hydrates in the subsequent cooling steps is much higher than that in the first one, which comes from the "memory effect" [14]. It should be noted here that freshly prepared THF or $d$-THF solutions are cloudy, but they become clear after one cooling-heating cycle. Whether the memory effect is due to the state of solutions is unclear at this point. In the THF-rich region, only one peak is observed in all cooling steps, which corresponds to the freezing of hydrates.

3.2. Heating Behavior. Figures 3 and 4 show heating behaviors in the $\mathrm{H}_{2} \mathrm{O}$-rich and THF-rich regions, respectively. In the $\mathrm{H}_{2} \mathrm{O}$-rich region, a sharp endothermic peak corresponds to the melting of the ice and some hydrate simultaneously, followed by a broad exothermic peak that is due to the dissociation of the rest of the hydrate sample. The small peak before the bulk melting event occurs where the heating rate was changed from 1.2 to $0.1 \mathrm{~K} \mathrm{~min}^{-1}$. The heating rate of $0.1 \mathrm{~K} \mathrm{~min}^{-1}$ was selected based on measurements of the eutectic and liquidus (also called "melting") temperatures as a function of the heating rate, as shown in Table 1. 


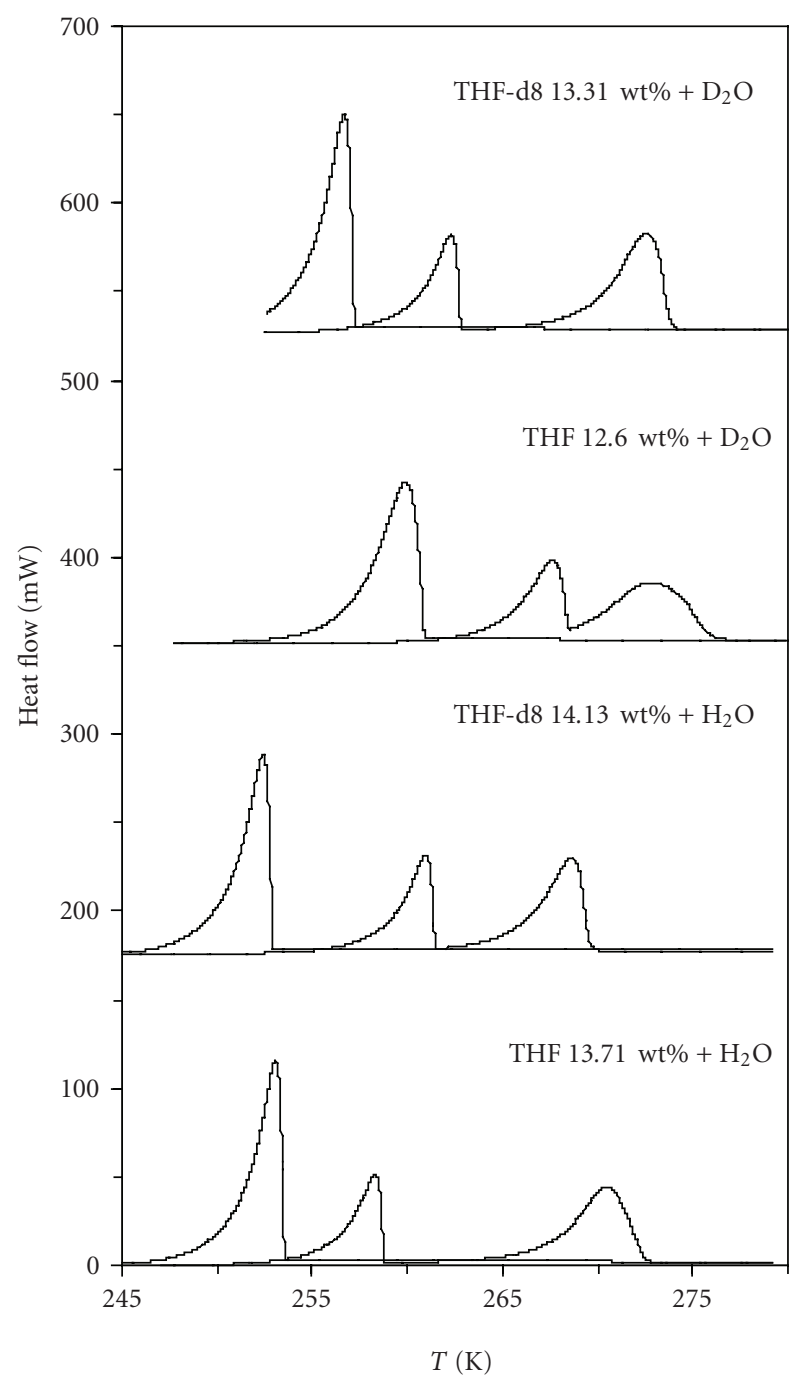

Figure 2: Cooling thermograms in $\mathrm{H}_{2} \mathrm{O}$ - and $\mathrm{D}_{2} \mathrm{O}$-rich regions. The thin line trace is the first cooling step; the heavy line is the subsequent cooling step.

TABLE 1: Eutectic and hydrate melting temperatures as a function of the heating rate for THF $(15.89 \mathrm{wt} \%)+\mathrm{H}_{2} \mathrm{O}$.

\begin{tabular}{lcc}
\hline Heat rate $\left(\mathrm{K} \mathrm{min}^{-1}\right)$ & Eutectic melting $(\mathrm{K})$ & Hydrate melting $(\mathrm{K})$ \\
\hline 0.1 & 272.03 & 278.09 \\
0.2 & 272.02 & 278.10 \\
0.5 & 271.96 & 278.23 \\
1.0 & 271.58 & 278.29 \\
\hline
\end{tabular}

At a heating rate below $0.2 \mathrm{~K} \mathrm{~s}^{-1}$, the eutectic temperature determined by the DSC used in this work is very close to the one $(272.01 \mathrm{~K})$ reported by Delahaye et al. [15], and the melting temperature does not change significantly under the same conditions. In the THF-rich regions, only one endothermic peak is observed that comes from the melting of hydrates.

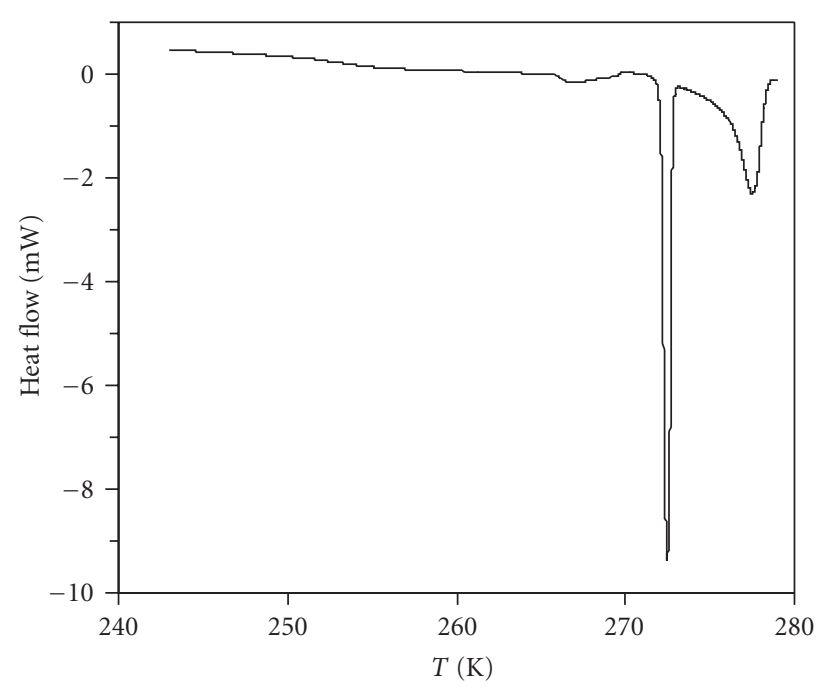

FIGURE 3: Heating thermogram for the THF (13.71\%)- $\mathrm{H}_{2} \mathrm{O}$ system.

3.3. Isotope Effects. The eutectic and melting temperatures are listed in Table 2, and the melting temperatures are also plotted in Figure 5. For both the host and the guest, the substitution of deuterium for hydrogen gives rise to statistically significant differences in the location of the liquidus. Several trends are observed. First, an increase of approximately 3$4 \mathrm{~K}$ in the hydrate melting temperature with heavy water is observed. Second, the eutectic temperatures increase by roughly $3.8 \mathrm{~K}$ with heavy water. These increases are close to difference $(3.8 \mathrm{~K})$ in the melting temperatures of ice and deuterated ice. Third, inclusion of deuterated THF causes an unexpected depression of the hydrate melting temperatures. The decrease ranges from (0.4-1.2) K for hydrogenated host and $(0.6-1.0) \mathrm{K}$ for deuterated host. Fourth, the eutectic temperature of THF-containing systems is $(0.03-0.18) \mathrm{K}$ higher than that in THF- $d 8$-containing systems for both $\mathrm{H}_{2} \mathrm{O}$ and $\mathrm{D}_{2} \mathrm{O}$. The eutectic temperatures of $\mathrm{C}_{4} \mathrm{H}_{8} \mathrm{O}-\mathrm{H}_{2} \mathrm{O}$, $\mathrm{C}_{4} \mathrm{D}_{8} \mathrm{O}-\mathrm{H}_{2} \mathrm{O}, \mathrm{C}_{4} \mathrm{H}_{8} \mathrm{O}-\mathrm{D}_{2} \mathrm{O}$, and $\mathrm{C}_{4} \mathrm{D}_{8} \mathrm{O}-\mathrm{D}_{2} \mathrm{O}$ systems are $272.06,271.95,275.78$, and $275.68 \mathrm{~K}$, respectively.

The melting points in the THF- $\mathrm{H}_{2} \mathrm{O}$ and THF- $\mathrm{D}_{2} \mathrm{O}$ systems are close to those reported by Hanley et al. [12]. Figure 6 shows their results along with the melting temperatures obtained in this study. These results show clearly the stabilizing effect of deuteration of the host, due to an increase in the strength of the hydrogen bonds, and the results presented here also indicate a small but statistically significant depression of the melting temperature when deuterated guests are enclathrated. Thus, the deuteration of the host causes an opposite effect on the melting temperatures from that of the guest. One possible explanation for this is that, for a given isotopic makeup of the host, the hydrogenated guest provides a greater entropic stabilization [16] of the hydrate structure relative to the liquid components. The mode of entropic stabilization involves guest vibrational motions, which for THF- $d 8$ encompass a lower range of frequencies than those of hydrogenated THF. In terms of hydrate properties, guest vibrations have 


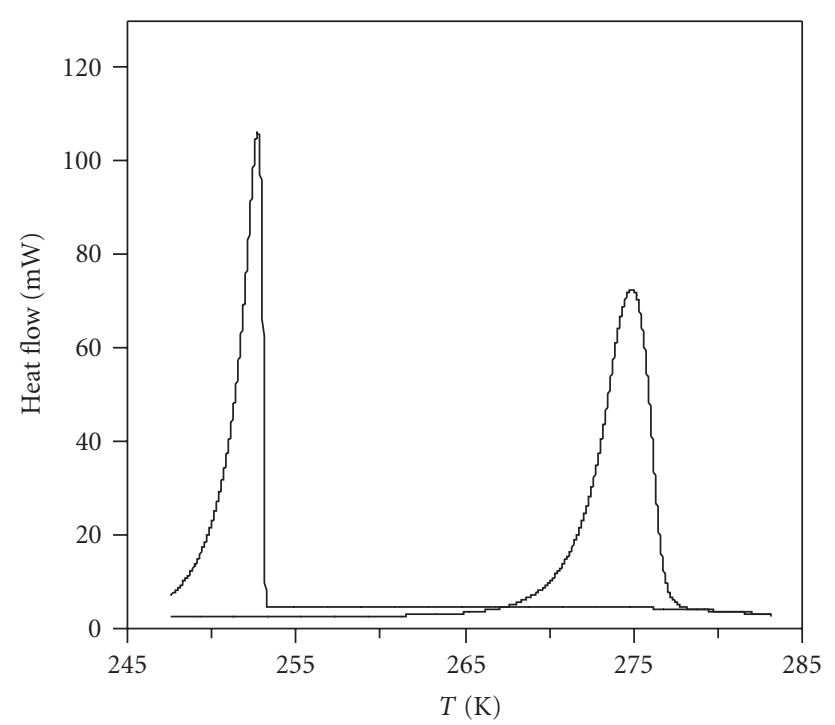

(a)

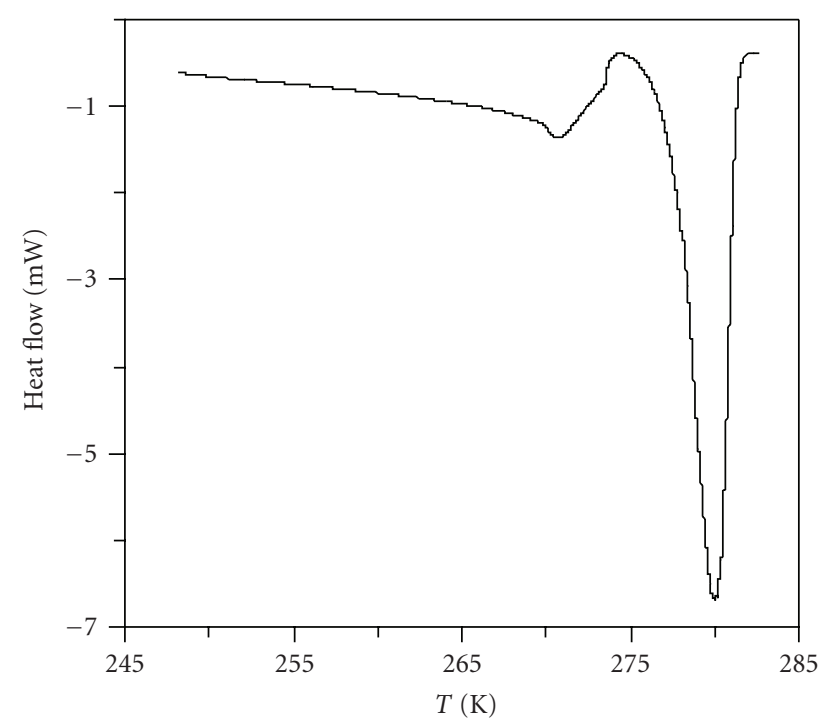

(b)

FIGURE 4: Cooling (a) and heating (b) thermograms for the THF (40.47 wt $\%)-\mathrm{D}_{2} \mathrm{O}$ system.

an enormous impact: low-frequency guest vibrations have been shown unambiguously to contribute to the low-thermal conductivity of clathrate hydrates by means of resonant scattering of lattice acoustic vibrations [17]. Beyond their impact on the thermal conductivity, guest vibrations must also play a role in the stability of the hydrate through guesthost interactions. More specifically, the rotational dynamics of large guests in general, and of large, polar guests such as THF in particular, might change sufficiently with deuteration to affect their ability to rotate within the cage potential. For polar guests, dipolar interactions and hydrogen bonding with the host could increase and lead to a decrease in the stability of the hydrate. Studies of deuterated guest molecules

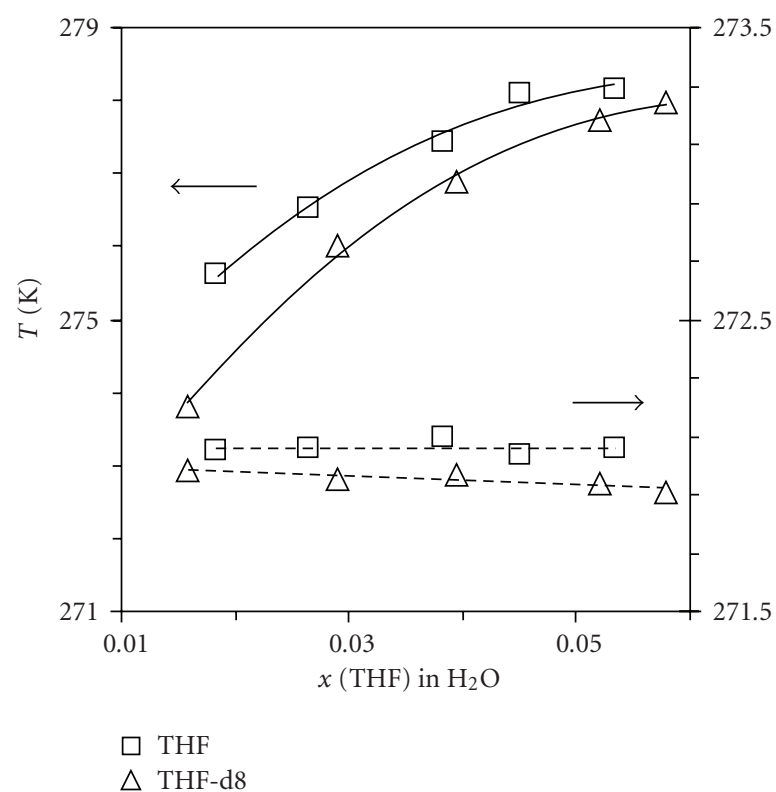

(a)

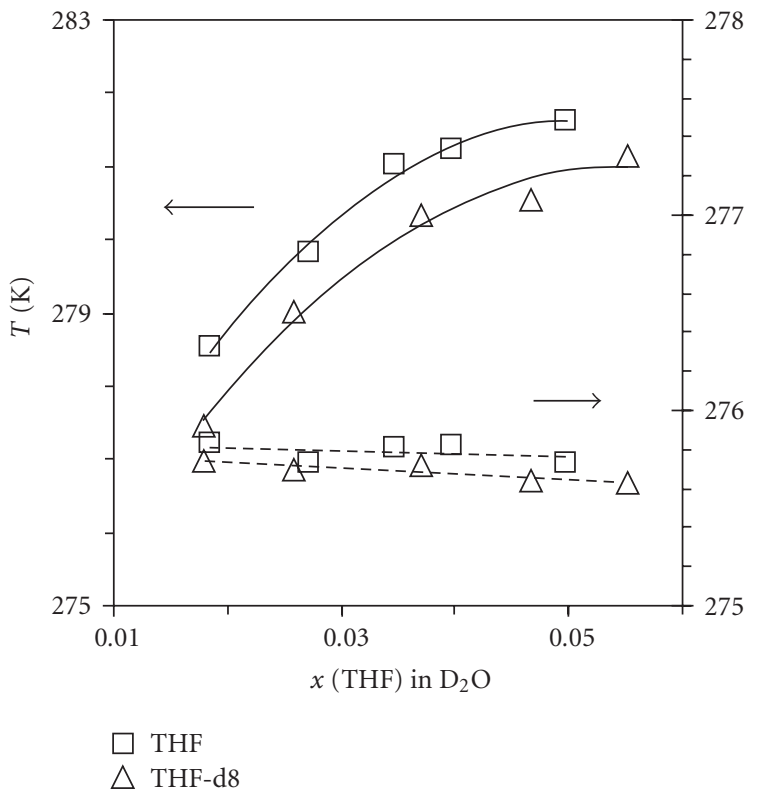

(b)

FIGURE 5: Effect of the isotopic composition of the THF guests on the melting points of hydrates (-) and eutectic melting of hydrate/ice mixtures (- - ) in $\mathrm{H}_{2} \mathrm{O}(\mathrm{a})$ and $\mathrm{D}_{2} \mathrm{O}(\mathrm{b})$.

could therefore provide a means of examining the effect of a change in guest vibrations on thermal conductivity and other properties, while keeping the size of the guest constant.

\section{Conclusion}

In this study, we have used microcalorimetry to determine the effect of isotopic substitution on the eutectic and hydrate 


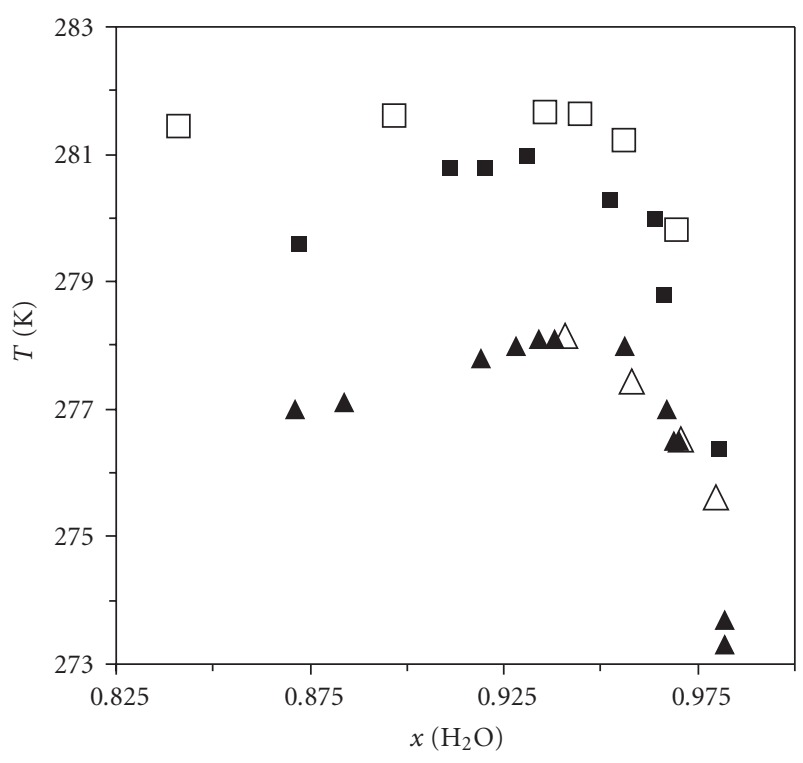

Figure 6: Melting points of THF- $\mathrm{H}_{2} \mathrm{O}$ (triangles) and THF$\mathrm{D}_{2} \mathrm{O}$ (squares) mixtures obtained by Hanley and coworkers (filled symbols) and in this work (open symbols).

TABLE 2: Eutectic and melting points for the four isotopic THFwater mixtures. The temperatures reported are averages of 3-6 measurements; standard errors are reported for the $95 \%$ confidence limit.

\begin{tabular}{|c|c|c|}
\hline $\mathrm{Wt} \%$ & Eutectic & Hydrate melting \\
\hline \multicolumn{3}{|c|}{$\mathrm{THF}+\mathrm{H}_{2} \mathrm{O}$} \\
\hline 6.95 & $272.05 \pm 0.00$ & $275.62 \pm 0.04$ \\
\hline 9.80 & $272.06 \pm 0.01$ & $276.52 \pm 0.08$ \\
\hline 13.71 & $272.10 \pm 0.01$ & $277.44 \pm 0.03$ \\
\hline 15.89 & $272.04 \pm 0.01$ & $278.09 \pm 0.02$ \\
\hline 18.43 & $272.06 \pm 0.00$ & $278.15 \pm 0.03$ \\
\hline \multicolumn{3}{|c|}{ THF- $d 8+\mathrm{H}_{2} \mathrm{O}$} \\
\hline 6.02 & $271.98 \pm 0.00$ & $273.82 \pm 0.02$ \\
\hline 10.67 & $271.96 \pm 0.01$ & $276.02 \pm 0.06$ \\
\hline 14.13 & $271.97 \pm 0.01$ & $276.89 \pm 0.02$ \\
\hline 18.00 & $271.94 \pm 0.00$ & $277.73 \pm 0.02$ \\
\hline 19.72 & $271.91 \pm 0.01$ & $277.98 \pm 0.03$ \\
\hline \multicolumn{3}{|c|}{$\mathrm{THF}+\mathrm{D}_{2} \mathrm{O}$} \\
\hline 7.00 & $275.83 \pm 0.01$ & $278.53 \pm 0.03$ \\
\hline 10.08 & $275.73 \pm 0.05$ & $279.82 \pm 0.04$ \\
\hline 12.60 & $275.81 \pm 0.02$ & $281.02 \pm 0.02$ \\
\hline 14.19 & $275.82 \pm 0.02$ & $281.22 \pm 0.02$ \\
\hline 17.34 & $275.73 \pm 0.02$ & $281.61 \pm 0.01$ \\
\hline \multicolumn{3}{|c|}{ THF- $d 8+\mathrm{D}_{2} \mathrm{O}$} \\
\hline 6.78 & $275.74 \pm 0.01$ & $277.46 \pm 0.02$ \\
\hline 9.57 & $275.70 \pm 0.00$ & $279.01 \pm 0.04$ \\
\hline 13.31 & $275.72 \pm 0.00$ & $280.33 \pm 0.02$ \\
\hline 16.39 & $275.64 \pm 0.01$ & $280.54 \pm 0.05$ \\
\hline 18.91 & $275.63 \pm 0.02$ & $281.14 \pm 0.02$ \\
\hline
\end{tabular}

melting temperatures in water-THF system. We observed an increase of approximately $3-4 \mathrm{~K}$ in the hydrate melting temperature with heavy water and similar increases in the eutectic temperatures with heavy water. Enclathration of deuterated THF causes a depression of the hydrate melting temperatures by $(0.4-1.2) \mathrm{K}$ for hydrogenated host and (0.6-1.0) K for deuterated host. In addition, the eutectic temperature of THF-containing systems is $(0.03-0.18) \mathrm{K}$ higher than that in THF-d8-containing systems for both $\mathrm{H}_{2} \mathrm{O}$ and $\mathrm{D}_{2} \mathrm{O}$. These results suggest that guest motions affect the thermodynamic stability of hydrates and call for more extensive calorimetric studies of phase equilibria and guest motions of deuterated molecules in a variety of clathrate hydrates as a test of the generality of the effects of guest vibrations on thermal conductivity and other properties, while the size of the guest is kept constant.

\section{Acknowledgment}

The authors are grateful for the support of National Science Foundation for this work under Grant no. CBET-0854210.

\section{References}

[1] Y. Zhang, P. G. Debenedetti, R. K. Prud'homme, and B. A. Pethica, "Differential scanning calorimetry studies of clathrate hydrate formation," Journal of Physical Chemistry B, vol. 108, no. 43, pp. 16717-16722, 2004.

[2] T. C. W. Mak and R. K. McMullan, "Polyhedral clathrate hydrates. X. Structure of the double hydrate of tetrahydrofuran and hydrogen sulfide," The Journal of Chemical Physics, vol. 42, no. 8, pp. 2732-2737, 1965.

[3] D. W. Davidson, M. M. Davies, and K. Williams, "Dielectric absorption and molecular motion in gas hydrates," The Journal of Chemical Physics, vol. 40, no. 11, pp. 3449-3450, 1964.

[4] J. Matouš, J. P. Hrncirik, J. Novak, and J. Pick, "Liquid-liquid equilibrium in the system water-tetrahydrofuran," Collection of Czechoslovak Chemical Communications, vol. 35, pp. 19041905, 1970.

[5] V. Balevicius, N. Weiden, and A. Weiss, "Deuteron NMR relaxation, phase diagrams, and isotope effects in liquid mixtures of tetrahydrofuran $/ \mathrm{D}_{2} \mathrm{O} /$ salt," Berichte der BunsenGesellschaft, vol. 98, no. 6, pp. 785-792, 1994.

[6] J.-C. Rosso and L. Carbonnel, "Le système binaire eautétrahydrofuanne," Comptes Rendus de l'Académie des Sciences Série C, vol. 273, pp. 15-18, 1971.

[7] L. Carbonnel and J.-C. Rosso, "Les clathrates des ethers cycliques. Leur stoéchiométrie déduite des diagrammes de phases eau-ethers cycliques," Journal of Solid State Chemistry, vol. 8, no. 4, pp. 304-311, 1973.

[8] R. Anderson, A. Chapoy, and B. Tohidi, "Phase relations and binary clathrate hydrate formation in the system $\mathrm{H}_{2}$-THF$\mathrm{H}_{2} \mathrm{O}$," Langmuir, vol. 23, no. 6, pp. 3440-3444, 2007.

[9] M. Zakrzewski, D. D. Klug, and J. A. Ripmeester, "On the pressure-induced phase transformation in the structure II clathrate hydrate of tetrahydrofuran," Journal of Inclusion Phenomena and Molecular Recognition in Chemistry, vol. 17, no. 3, pp. 237-247, 1994.

[10] A. Yu. Manakov, S. V. Goryainov, A. V. Kurnosov, A. Yu. Likhacheva, Y. A. Dyadin, and E. G. Larionov, "Clathrate nature of the high-pressure tetrahydrofuran hydrate phase and 
some new data on the phase diagram of the tetrahydrofuranwater system at pressures up to $3 \mathrm{GPa}$," Journal of Physical Chemistry B, vol. 107, no. 31, pp. 7861-7866, 2003.

[11] A. Oleinikova and H. Weingärtner, "Isotope effect on the coexistence curve and crossover behavior of water + tetrahydrofuran," Chemical Physics Letters, vol. 319, no. 1-2, pp. 119 $124,2000$.

[12] H. J. M. Hanley, G. J. Meyers, J. W. White, and E. D. Sloan, "The melting curve of tetrahydrofuran hydrate in $\mathrm{D}_{2} \mathrm{O}$," International Journal of Thermophysics, vol. 10, no. 4, pp. 903909, 1989.

[13] J. S. Zhang and J. W. Lee, "Equilibrium of hydrogen + cyclopentane and carbon dioxide + cyclopentane binary hydrates," Journal of Chemical and Engineering Data, vol. 54, no. 2, pp. 659-661, 2009.

[14] S. Takeya, A. Hori, T. Hondoh, and T. Uchida, "Freezingmemory effect of water on nucleation of $\mathrm{CO}_{2}$ hydrate crystals," Journal of Physical Chemistry B, vol. 104, no. 17, pp. 41644168, 2000.

[15] A. Delahaye, L. Fournaison, S. Marinhas, et al., "Effect of THF on equilibrium pressure and dissociation enthalpy of $\mathrm{CO}_{2}$ hydrates applied to secondary refrigeration," Industrial and Engineering Chemistry Research, vol. 45, no. 1, pp. 391-397, 2006.

[16] M. A. White, D. C. MacLaren, R. A. Marriott, and B.-Z. Zhan, "Thermodynamic stability of clathrate hydrates relative to their separate chemical components," Canadian Journal of Physics, vol. 81, no. 1-2, pp. 175-182, 2003.

[17] J. S. Tse, V. P. Shpakov, V. R. Belosludov, F. Trouw, Y. P. Handa, and W. Press, "Coupling of localized guest vibrations with the lattice modes in clathrate hydrates," Europhysics Letters, vol. 54, no. 3, pp. 354-360, 2001. 

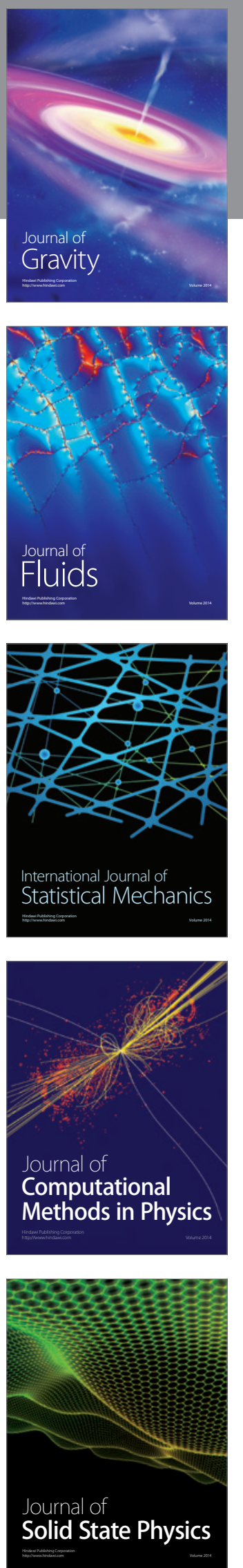

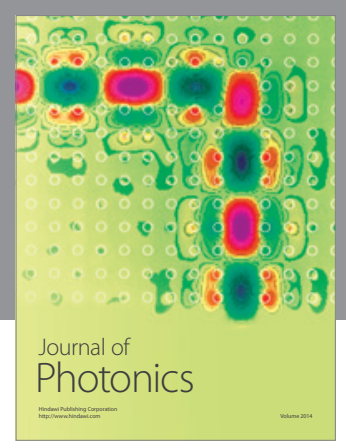

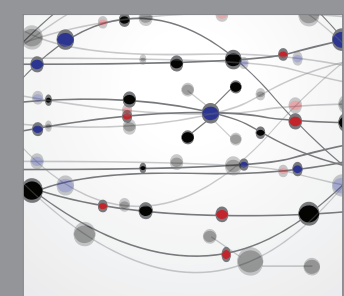

The Scientific World Journal
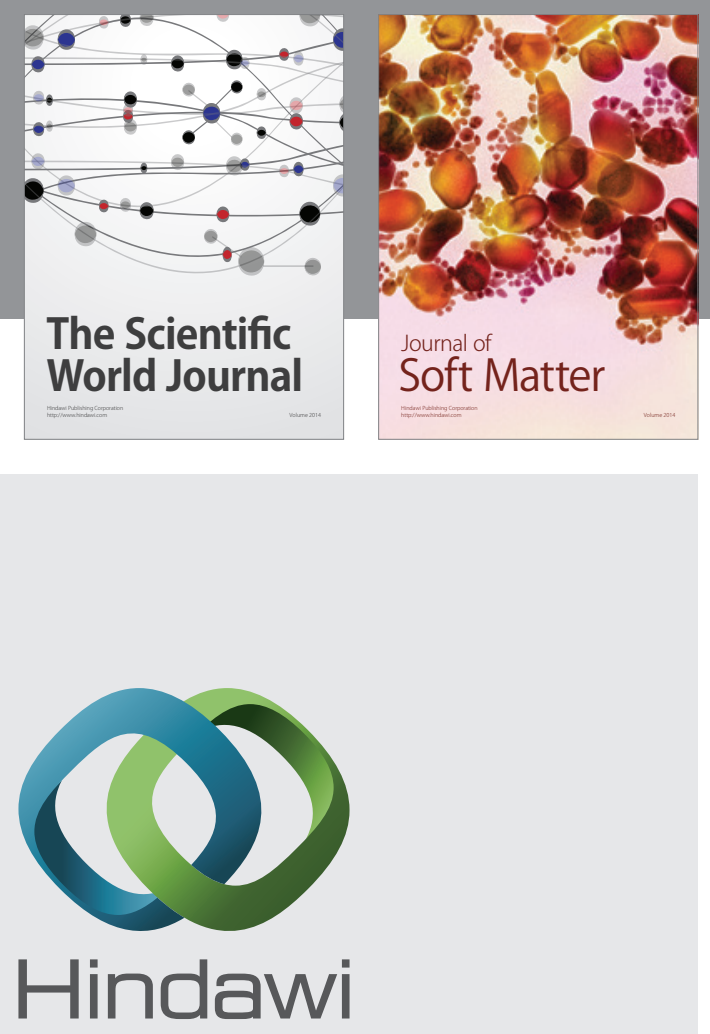

Submit your manuscripts at

http://www.hindawi.com
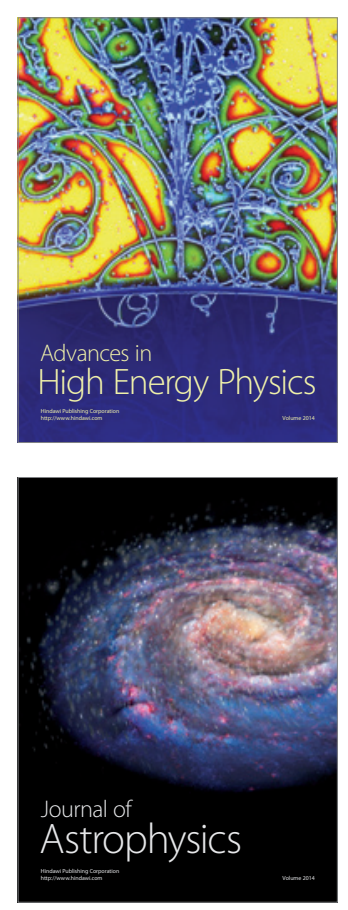
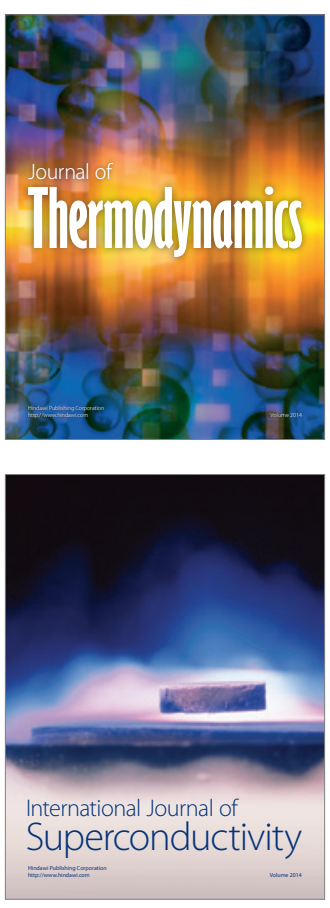
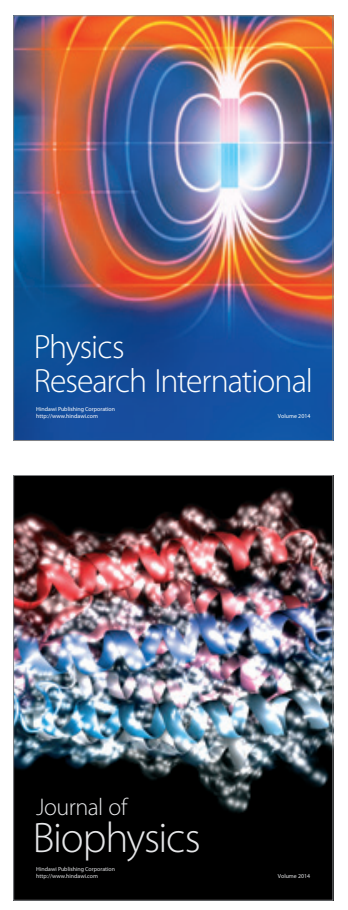
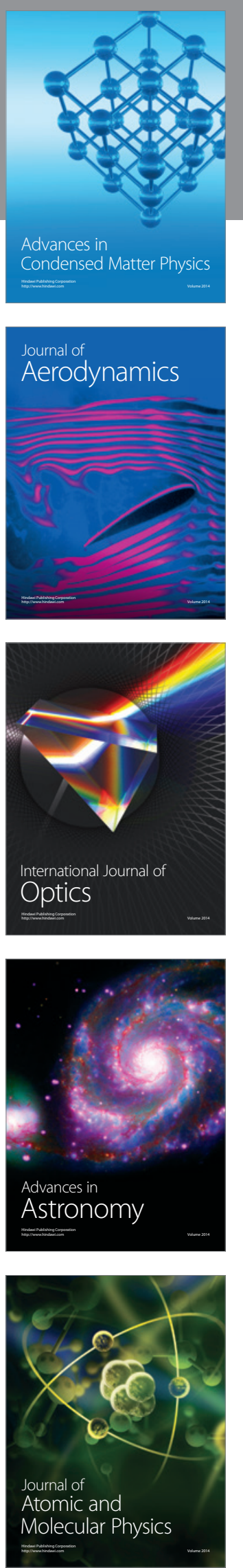